\title{
Effects of Maternal Age and Age-Specific Preterm Birth Rates on Overall Preterm Birth Rates — United States, 2007 and 2014
}

\author{
Cynthia Ferré, MA ${ }^{1}$; William Callaghan, $\mathrm{MD}^{1}$; Christine Olson, $\mathrm{MD}^{1}$; Andrea Sharma, $\mathrm{PhD}^{1}$; Wanda Barfield, $\mathrm{MD}^{1}$
}

Reductions in births to teens and preterm birth rates are two recent public health successes in the United States $(1,2)$. From 2007 to 2014 , the birth rate for females aged 15-19 years declined $42 \%$, from 41.5 to 24.2 per 1,000 females. The preterm birth rate decreased $8.4 \%$, from $10.41 \%$ to $9.54 \%$ of live births (1). Rates of preterm births vary by maternal age, being higher among the youngest and oldest mothers. It is unknown how changes in the maternal age distribution in the United States have affected preterm birth rates. CDC used birth data to assess the relative contributions of changes in the maternal age distribution and in age-specific preterm birth rates to the overall decrease in preterm birth rates. The preterm birth rate declined in all age groups. The effects of age distribution changes on the preterm birth rate decrease were different in younger and older mothers. The decrease in the proportion of births to mothers aged $\leq 19$ and 20-24 years and reductions in age-specific preterm rates in all age groups contributed to the overall decline in the preterm birth rate. The increase in births to mothers aged $\geq 30$ years had no effect on the overall preterm birth rate decrease. The decline in preterm births from 2007 to 2014 is related, in part, to teen pregnancy prevention and the changing maternal age distribution. Effective public health strategies for further reducing preterm birth rates need to be tailored to different age groups.

National Vital Statistics System data for all live births to U.S. residents in 2007 and 2014 were analyzed for the effects of maternal age on the decline in preterm birth rates. The analysis was limited to births with gestational age $\geq 20$ weeks, as determined by the obstetric estimate. The year 2007 was the first year the obstetric estimate was available nationally $(1,3)$. The year 2014 was the most recent year with final birth data available at the time of analysis. Preterm birth rates were defined as $<37$ completed weeks of gestation and expressed as a percentage of live births. Maternal age was categorized as $\leq 19$,
20-24, 25-29, 30-34, and $\geq 35$ years. Using rate decomposition methods, the change in preterm birth rates from 2007 to 2014 was divided into two components: 1) changes in the maternal age distribution, and 2) changes in the age-specific preterm birth rates (4). The two components were calculated relative to each other; one was held constant (by using the average value for the 2 years) as the observed variation in the other component was assessed. The sum of the two components across the age groups equaled the total preterm birth rate difference (4).

From 2007 to 2014, maternal age increased from a mean of 27.4 years to 28.3 years (Figure). A decrease in the percentage of births to mothers aged $\leq 24$ years was observed, which included a $39.5 \%$ decrease in births to teens and an increase in births to women aged $\geq 25$ years (Table).

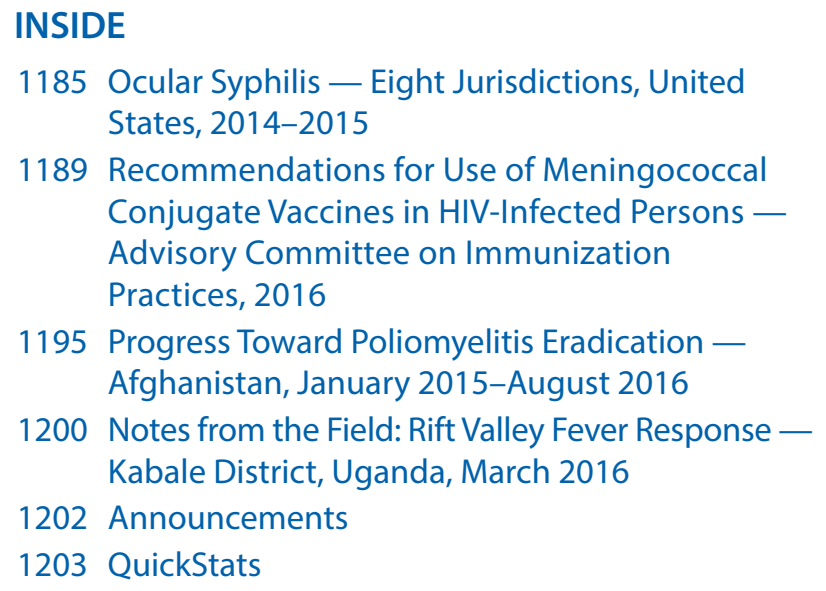

Continuing Education examination available at http://www.cdc.gov/mmwr/cme/conted_info.html\#weekly.

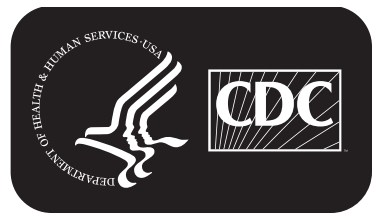


FIGURE. Percentages of live births (LBs) and preterm births (PTBs), by maternal age — United States, 2007 and 2014

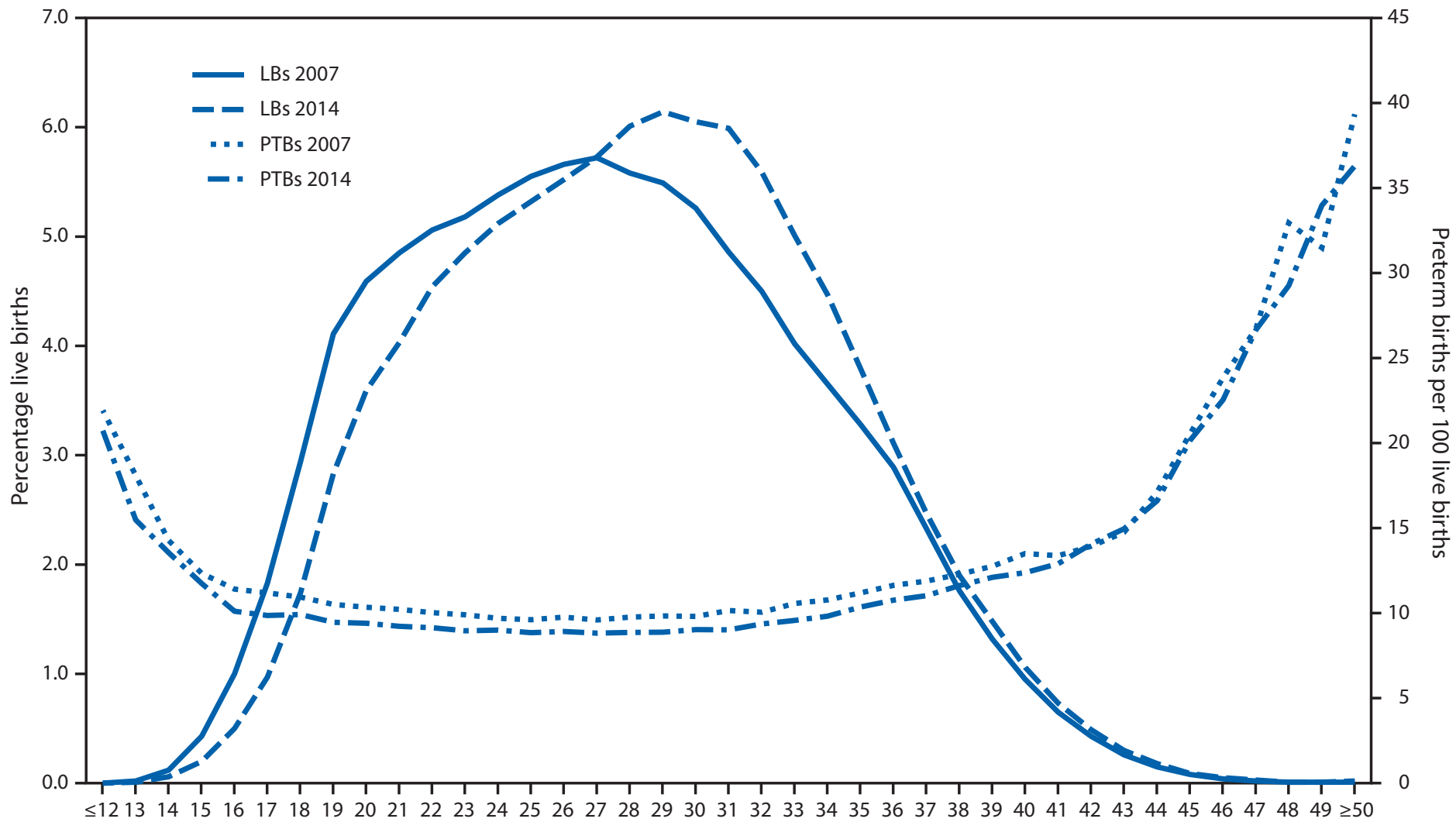

Maternal age (yrs)

The MMWR series of publications is published by the Center for Surveillance, Epidemiology, and Laboratory Services, Centers for Disease Control and Prevention (CDC), U.S. Department of Health and Human Services, Atlanta, GA 30329-4027.

Suggested citation: [Author names; first three, then et al., if more than six.] [Report title]. MMWR Morb Mortal Wkly Rep 2016;65:[inclusive page numbers].

\section{Centers for Disease Control and Prevention}

Thomas R. Frieden, MD, MPH, Director

Harold W. Jaffe, MD, MA, Associate Director for Science

Joanne Cono, MD, ScM, Director, Office of Science Quality

Chesley L. Richards, MD, MPH, Deputy Director for Public Health Scientific Services

Michael F. Iademarco, MD, MPH, Director, Center for Surveillance, Epidemiology, and Laboratory Services

\section{MMWR Editorial and Production Staff (Weekly)}

Sonja A. Rasmussen, MD, MS, Editor-in-Chief

Charlotte K. Kent, PhD, MPH, Executive Editor

Jacqueline Gindler, MD, Editor

Teresa F. Rutledge, Managing Editor

Douglas W. Weatherwax, Lead Technical Writer-Editor

Stacy A. Benton, Soumya Dunworth, PhD, Teresa M. Hood, MS, Technical Writer-Editors

Timothy F. Jones, MD, Chairman

Matthew L. Boulton, MD, MPH

Virginia A. Caine, MD

Katherine Lyon Daniel, PhD

Jonathan E. Fielding, MD, MPH, MBA

David W. Fleming, MD

\section{MMWR Editorial Board}

William E. Halperin, MD, DrPH, MPH

King K. Holmes, MD, PhD

Robin Ikeda, MD, MPH

Rima F. Khabbaz, MD

Phyllis Meadows, PhD, MSN, RN

Jewel Mullen, MD, MPH, MPA
Martha F. Boyd, Lead Visual Information Specialist

Maureen A. Leahy, Julia C. Martinroe,

Stephen R. Spriggs, Moua Yang, Tong Yang, Visual Information Specialists

Quang M. Doan, MBA, Phyllis H. King, Terraye M. Starr, Information Technology Specialists 
Morbidity and Mortality Weekly Report

TABLE. Number and percentage of all births and preterm births and the components of the preterm rate change, by maternal age — United States, 2007 and 2014

\begin{tabular}{|c|c|c|c|c|c|c|c|c|c|}
\hline \multirow{3}{*}{$\begin{array}{l}\text { Maternal } \\
\text { age (yrs) }\end{array}$} & \multicolumn{3}{|c|}{ All births } & \multicolumn{3}{|c|}{ Preterm births } & \multicolumn{3}{|c|}{ Rate change components* } \\
\hline & 2007 & 2014 & \multirow{2}{*}{$\begin{array}{c}\% \\
\text { Change }\end{array}$} & 2007 & 2014 & \multirow{2}{*}{$\begin{array}{c}\text { Rate } \\
\text { difference }\end{array}$} & \multirow{2}{*}{$\begin{array}{c}\text { Age } \\
\text { distribution }\end{array}$} & \multirow{2}{*}{$\begin{array}{l}\text { Age-specific } \\
\text { rate }\end{array}$} & \multirow[b]{2}{*}{ Total effect } \\
\hline & No. (\%) & No. (\%) & & No. (\%) & No. (\%) & & & & \\
\hline$<20$ & $448,461(10.4)$ & $251,467(6.3)$ & -39.5 & 49,222 (10.98) & 24,707 (9.82) & -1.15 & -0.43 & -0.10 & -0.53 \\
\hline $20-24$ & $1,076,492(25.1)$ & $881,395(22.1)$ & -11.7 & 107,989 (10.03) & 80,477 (9.13) & -0.90 & -0.28 & -0.21 & -0.49 \\
\hline $25-29$ & $1,202,608(28.0)$ & $1,144,008(28.7)$ & 2.6 & $116,846(9.72)$ & $101,450(8.87)$ & -0.85 & 0.07 & -0.24 & -0.17 \\
\hline $30-34$ & $957,551(22.3)$ & $1,080,027(27.1)$ & 21.6 & 97,982 (10.23) & $100,750(9.33)$ & -0.90 & 0.47 & -0.22 & 0.25 \\
\hline$\geq 35$ & $609,370(14.2)$ & $626,513(15.7)$ & 10.8 & $74,977(12.30)$ & $72,523(11.58)$ & -0.73 & 0.18 & -0.11 & 0.08 \\
\hline Total & $4,294,482(100)$ & $3,983,410(100)$ & NA & $447,016(10.41)$ & 379,901 (9.54) & -0.87 & 0.01 & -0.88 & -0.87 \\
\hline
\end{tabular}

Abbreviation: $\mathrm{NA}=$ not applicable.

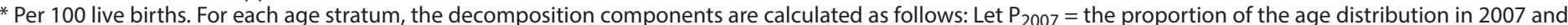

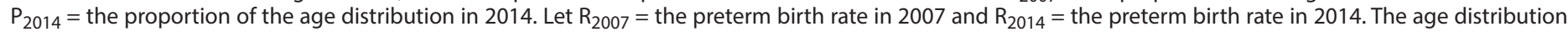
component $=\left(P_{2014}-P_{2007}\right) \times\left[\left(R_{2007}+R_{2014}\right) / 2\right]$. The age-specific rate component $=\left(R_{2014}-R_{2007}\right) \times\left[\left(P_{2007}+P_{2014}\right) / 2\right]$.

From 2007 to 2014, the preterm birth rate decreased from $10.41 \%$ to $9.54 \%$, an absolute rate difference of $-0.87 \%$ (Table). A U-shaped relationship between maternal age and preterm birth was present in both years with the lowest preterm birth rate occurring among women aged 25-29 years (Table) (Figure). The decrease in preterm birth rates from 2007 to 2014 was observed for mothers at all ages $<42$ years. The absolute rate difference was highest among teens and lowest among women aged $\geq 35$ years (Table).

The decomposition analysis partitioned the overall observed rate difference of $-0.87 \%$ into two parts, age distribution and age-specific rate components (Table). The change in age distribution contributed to the preterm birth rate decrease (as indicated by the negative values) only among mothers aged $\leq 24$ years. In contrast, the age distribution component for mothers aged $\geq 25$ years, and especially for mothers aged $\geq 30$ years, offset this decline. When the age distribution components were summed across the age groups, a negligible effect (0.01) was observed on the overall change in preterm birth rates. The change in age-specific preterm birth rates contributed to the decline in preterm birth rate across all age groups.

Examining the total effect of both components on the preterm birth rate decline by age group, the largest total effects were observed among mothers aged $\leq 19$ and mothers aged 20-24 years (Table). In these two groups, the change in age distribution had a larger effect than the change in the agespecific preterm birth rate. For mothers aged 25-29 years, the total effect also contributed to the overall preterm birth rate decline because the age-specific rate component was greater than the age distribution component. For mothers aged $\geq 30$ years, the total effect of both components did not contribute to the overall preterm birth rate decrease; the rate increases from the age distribution components were greater than the rate decreases from the age-specific rate components.

These analyses included all births; however, sensitivity analyses restricting to singleton births produced similar results.
The overall absolute rate difference for singletons during this period was $-0.85 \%$, compared with the $-0.87 \%$ for all births.

\section{Discussion}

The overall decline in the preterm birth rate from 2007 to 2014 was related to declines in age-specific preterm birth rates and a decrease in prevalence of births to teens and women aged $20-24$ years. The contribution from mothers aged $\geq 24$ years to the age-distribution component was offset by an increased prevalence of births to older mothers who have high rates of preterm birth. Thus, the total age distribution component masked divergent influences of younger and older mothers on the overall preterm birth rate decline. Because of this, the influence of younger mothers on the overall preterm birth rate decline is more appropriately indicated by examining the agespecific total effects in the decomposition analysis. Considering relative effects of both age distribution and age-specific preterm birth rate components, only mothers aged $\leq 29$ years contributed to the overall rate decline, with the largest contributions from teens and women aged 20-24 years.

Other studies have documented increased preterm birth rates among teen and older mothers compared with mothers in their mid-twenties to early thirties (5). Although teen and older mothers might share some common preterm birth risk factors, such as low socioeconomic status, extremes of body mass index, and smoking, physiologic immaturity is a risk factor for teen mothers and the prevalence of preexisting chronic disease is greater among older mothers $(5,6)$. This heterogeneity of risk for preterm births according to maternal age and the variation in changes in age-specific preterm birth rates, combined with the changes in maternal age distribution over time, suggest the need for varying preterm birth prevention strategies across the reproductive life span.

The findings in this report are subject to at least one limitation: the relationship of preterm birth with maternal age is associative, not causal. The analysis did not assess the impact 


\section{Summary}

What is already known about this topic?

Rates of births to teens and of preterm births declined in the United States from 2007 to 2014. Preterm births are more common among the youngest and oldest mothers.

What is added by this report?

Preterm birth rates declined for all age groups and overall from $10.41 \%$ to $9.54 \%$ of live births. Mean maternal age increased from 27.4 years to 28.3 years. The contribution of fewer births to teens and to women aged 20-24 years to the overall decline in preterm births was offset by increases in births to older mothers.

What are the implications for public health practice?

The changing distribution of maternal age might indicate success of programs to prevent teen and unintended pregnancies. Effective public health strategies for further reducing preterm birth rates need to be tailored to different age groups.

of other pregnancy outcomes, such as elective termination or fetal death, or of potential confounders, such as maternal race/ ethnicity, obstetric history, smoking, socioeconomic status, body mass index, chronic or pregnancy-related conditions, prenatal care, and delivery method (5-7). The effects on preterm birth rates of maternal 17-hydroxyprogesterone use, a preterm birth prevention strategy that increased during this period $(\sigma)$, were not examined and the effects of maternal age on spontaneous, medically indicated, early, or late preterm births were not assessed.

The overall decline in the preterm birth rate from 2007 to 2014 is related in part to the changing maternal age distribution associated with the success of teen pregnancy prevention and declines in unintended pregnancy (8). Teen pregnancy prevention is one of CDC's Winnable Battles (9). Although teen pregnancy prevention and family planning have many positive health and societal effects, the results of this analysis suggest these programs might also have direct effects on reducing preterm birth rates. Based on recent data, $75 \%$ of pregnancies to teens aged $15-19$ years and $59 \%$ of pregnancies to women aged $20-24$ years are unintended (8). The need for prevention of first and repeat teen pregnancies (10) continues. Prevention of unintended pregnancy and encouragement of optimal birth spacing is one part of a five-part strategy for preterm birth prevention (7). Other strategies include improved access to preconception care, preterm birth risk identification and treatment, reduction of elective delivery before 39 weeks gestation, and single embryo transfer in assisted reproductive technology (7). These strategies need to be implemented throughout the reproductive life span to reduce preterm births for all maternal ages.

\section{Acknowledgment}

Thomas R. Frieden, Office of the Director, CDC.

${ }^{1}$ Division of Reproductive Health, National Center for Chronic Disease Prevention and Health Promotion, CDC.

Corresponding author: Cynthia Ferré, cferre@cdc.gov, 770-488-6268.

\section{References}

1. Hamilton BE, Martin JA, Osterman MJ, Curtin SC, Matthews TJ. Births: final data for 2014. Natl Vital Stat Rep 2015;64:1-64.

2. Romero L, Pazol K, Warner L, et al. Reduced disparities in birth rates among teens aged 15-19 years-United States, 2006-2007 and 2013-2014. MMWR Morb Mortal Wkly Rep 2016;65:409-14. http:// dx.doi.org/10.15585/mmwr.mm6516a1

3. Martin JA, Osterman MJ, Kirmeyer SE, Gregory EC. Measuring gestational age in vital statistics data: transitioning to the obstetric estimate. Natl Vital Stat Rep 2015;64:1-20.

4. Kitagawa E. Components of a difference between two rates. J Am Stat Assoc 1955;50:1168-94.

5. Institute of Medicine (US) Committee on Understanding Premature Birth and Assuring Healthy Outcomes. Preterm birth: causes, consequences, and prevention. Washington, DC: National Academies Press, 2007.

6. Committee on Practice Bulletins-Obstetrics, The American College of Obstetricians and Gynecologists. Practice bulletin no. 130: prediction and prevention of preterm birth. Obstet Gynecol 2012;120:964-73. http://dx.doi.org/10.1097/AOG.0b013e3182723b1b

7. Shapiro-Mendoza CK, Barfield WD, Henderson Z, et al. CDC grand rounds: public health strategies to prevent preterm birth. MMWR Morb Mortal Wkly Rep 2016;65:826-30. http://dx.doi.org/10.15585/mmwr. mm6532a4

8. Finer LB, Zolna MR. Declines in unintended pregnancy in the United States, 2008-2011. N Engl J Med 2016;374:843-52. http://dx.doi. org/10.1056/NEJMsa1506575

9. CDC. Winnable battles: teen pregnancy. Atlanta, GA: US Department of Health and Human Services, CDC; 2016. http://www.cdc.gov/ winnablebattles/teenpregnancy/index.html

10. CDC. Vital signs: repeat births among teens_United States, 20072010. MMWR Morb Mortal Wkly Rep 2013;62:249-55. 